\title{
Influence of Surface Modification on Physical, Mechanical, and Morphological Properties of Natural Single Areca catechu Fiber
}

\author{
RAGHU PATEL G. RANGANAGOWDA, SAKSHI SHANTHARAM KAMATH, \\ RAVI KUMAR CHANDRAPPA and BASAVARAJU BENNEHALLI*
}

Department of Chemistry, Alva's Institute of Engineering and Technology, Mijar-574225, Karnataka, India.

${ }^{*}$ Corresponding author E-mail: basavaraju@ aiet.org.in

http://dx.doi.org/10.13005/ojc/350214

(Received: October 02, 2018; Accepted: March 10, 2019)

\begin{abstract}
In the present study, fibers extracted from empty areca fruit were surface modified by giving chemical treatment with $2 \% \mathrm{NaOH}$ solution at laboratory temperature to investigate the effect of alkali treatment on physical, mechanical, and morphological properties of Areca catechu fiber. Tensile strength and Young's modulus of areca fiber found to decrease with alkali treatment, but improvement in elongation at break of the fiber was observed for alkali treated fiber due to elimination of lignin and hemicelluloses from the fiber surface upon alkali treatment. The results proved that the natural Areca catechu fiber is a potential alternative source for strengthening the polymer composite industries.
\end{abstract}

Keywords: Areca catechu fiber, Alkali treatment, Tensile strength, Morphology.

\section{INTRODUCTION}

Synthetic, non-biodegradable and expensive glass, carbon and kevlar fibers are commonly used in the fabrication of polymer composites because of their outstanding physical and mechanical properties. Many researchers attracted towards environmental friendly natural fibers, as a promising alternative for synthetic fibers due to their abundance, renewability, biodegradability, low cost, good specific strength, good reinforcing properties, low density and nonabrasive nature ${ }^{1}$. Also, natural fibers are less hazardous compared to synthetic fibers.

Agricultural crop byproducts, wheat stalks, corn stalk, rice husk, sugar cane, bagasse, fruit peels, and pineapple leaves are some of the potential source of natural fibers. Utilization of these agricultural residues as a reinforcement material in polymer composites may help in management, development of light weight, strong, eco-friendly and lucrative products with diverse applications ${ }^{2-3}$.

The utilization of agricultural byproducts as reinforcement in composites has been reported by several researchers ${ }^{4-8}$. Pothana et al., reported the optimum percentages of banana fibre as $40 \mathrm{wt} \%$. Luo and Netravali have studied the mechanical properties of pineapple fibre based polymer composites ${ }^{10}$. Pavithran et al., studied the rupture energies of

This is an Open Access article licensed under a Creative Commons license: Attribution 4.0 International (CC- BY). Published by Oriental Scientific Publishing Company @ 2018

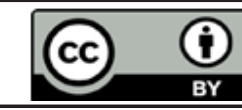


various natural fibre based polyester composites ${ }^{11}$. Karmaker and Schneider studied the mechanical properties of jute and kenaf fibre reinforced PP composites $^{12}$. Gowda et al., reported in their study that jute-polyester composites have shown improved strength than wood reinforced composites ${ }^{13}$. Okubo et al., discussed the mechanical properties of bamboo-PP composites ${ }^{14}$. Studies have been conducted on Natural Rubber based composites ${ }^{15-16}$. Sisal and short pineapple fibres have been used for the reinforcement and low density polyethylene ${ }^{17-25}$. Chakraborty et al., studied the properties of jutecarboxylated nitrile rubber composites ${ }^{26}$. Bledzki and Gassan reviewed the studies on composites reinforced with cellulosic fibres ${ }^{27}$. This literature study revealed that still a lot of research is needed in the field of natural fibers and natural fiber reinforced polymer composites to improve their properties.

Researches on using fibers from oil palm empty fruit, coir, sisal, jute, and banana stalkas reinforcement materials in polymer composites reported the improved mechanical properties of polymer composites ${ }^{28-29}$. The major disadvantage of utilizing natural fibers extracted from agricultural by products in composites development is the fiber hydrophilic nature, due to which there exist inaptness between the natural fiber and hydrophobic polymer matrix. Incompatibility leads to poor fiber and matrix interfacial adhesion and interruption of good stress transfer at the fiber-matrix interface which affects the mechanical properties of the developed composites. The compatibility between the hydrophilic natural fiber and hydrophobic polymer matrix is improved by surface alteration of the natural reinforcing fiber and many methods have been investigated.

The presence of hydrogen bonding reduces the reactivity of natural fibers towards the polymeric matrix and presence of hydroxyl groups in the natural fibers enables them to take part in chemical treatments. Thus, surface modifications may stimulate these hydroxyl groups or add new chemical groups that can efficiently improve the interfacial bonding of fibers with the polymeric resin. Surface modification by chemical treatments improves surface properties for example, wetting, attachment and surface strain or porosity of natural strands, reduces fiber's length dispersion and increases its aspect ratio.
Alkali, acetylation, acrylation, benzoylation, silane and permanganate treatment are the common surface treatments for natural fibers and among these treatments, alkali treatment is considered as more economical ${ }^{30}$. The process involves removal of pectin, wax, and lignin from the fiber surface with structural conversion of cellulose type I to cellulose type $\|^{31}$. A number of researchers have carried out work on the properties of alkali treated natural fiberreinforced polymer composites ${ }^{32-34}$. Most of present and past studies include studies on many different kinds of plant materials but very less attention has been made on areca fibers.

Areca catechu crops are cultivated in tropical climate countries. As per the economical analysis report by the Food and Agriculture of United Nation in the year 2016(Food and Agriculture Organization Corporate Statistical Database 2016); it is categorized as an important economic crop particularly in India (Table 1).

Table 1: Top ten Areca catechu plant growing countries and the production of areca nut in the year 2016 (Food and Agriculture Organization Corporate Statistical Database 2016)

\begin{tabular}{cc}
\hline Country & $\begin{array}{c}\text { Production } \\
\text { (Tonnes) }\end{array}$ \\
\hline India & 703,000 \\
Burma & 129,170 \\
Bangladesh & 121,113 \\
China & 99,992 \\
Indonesia & 54,057 \\
Srilanka & 44,059 \\
Thailand & 38,141 \\
Nepal & 14,225 \\
Bhutan & 9,858 \\
Malaysia & 312 \\
\hline
\end{tabular}

Areca catechu fibers, extracted from the empty fruits are presently used as housing insulation material and fabrication of value-added products such as cushion, handcrafts, and non-woven fabrics ${ }^{35}$. Karnataka is the largest areca plant growing state with a share around $50 \%$ of total areca plantation in the nation. Hence, a massive quantity of areca fiber is available for composite development and applications and appears to be a good alternative for synthetic fiber. Thus, to utilize these areca fibers as reinforcement, it needs an exhaustive study on physical, chemical and mechanical properties of Areca catechu fibers.

Few studies on the properties of polymer composites reinforced with areca fiber revealed 
that Areca catechu fiber has a good potential to be used as reinforcing material in composites after fiber surface modification ${ }^{33-39}$. Thus, in the present study, areca fibers were surface modified by giving chemical treatment with $2 \% \mathrm{NaOH}$ solution at laboratory temperature to study the effect of alkali treatment on physical, mechanical and morphological properties of areca fiber.

\section{Fiber Extraction}

\section{METHODS}

Areca catechu empty fruits were collected from Alva's farm house, Mijar, Karnataka, India. The dried areca empty fruits that were immersed in distilled water for a period of 5 days. This procedure is called retting; permitting the fiber to be extracted from the empty fruit effectively. The extracted areca strands were isolated by using a comb. The existing impurities and the broken fibers were removed by using a sieve. Then, the Areca catechu fibers were maintained at a temperature of $30^{\circ} \mathrm{C}$ and relative humidity of $70 \%$ for a period of $72 \mathrm{~h}$ prior to the surface treatments ${ }^{40-41}$.

\section{Surface Treatment}

The fibers were soaked in a glass beaker containing $2 \% \mathrm{NaOH}$ solution at room temperature $\left(30-32^{\circ} \mathrm{C}\right)$ for $1 \mathrm{~h}$. The alkali treated fibers were then immersed in distilled water for $24 \mathrm{~h}$ to remove the residual sodium hydroxide. Final washing was done with distilled water containing little amount of $2 \%$ acetic acid. Finally, fibers were dried in an oven at $70^{\circ} \mathrm{C}$ for $3 \mathrm{~h}$ to obtain alkali treated fibers.

\section{Fiber Tensile Strength}

The tensile strength of single Areca catechu fiber was determined according to ASTM D382201 method by using universal testing machine (Mecmesin, $2.5 \mathrm{xt}$ ) with gauge length, $20 \mathrm{~mm}$ at a cross head speed of $5 \mathrm{~mm} / \mathrm{min}$ with $100 \mathrm{~N}$ load cell. The influence of fiber length variation on testing was minimized by selecting 25 samples from each group ranging from 35-43 mm and after the measurement; average tensile strength is reported by neglecting the extreme values, if any.

\section{RESULTS AND DISCUSSIONS}

\section{Fiber Dimensions}

Fiber dimension is an important parameter in composite development as composite mechanical properties are dependent on cellulose content, aspect ratio and micro-fibrillar angle ${ }^{42}$. In the present study, 2000 areca fibers were randomly selected and dimensions were determined by using optical microscopy (Olympus SZ-PT).

The fiber length was measured by using a scale with an accuracy of $1 \mathrm{~mm}$ at laboratory temperature. The length was considered as a distance between the two ends of the extended fiber. In this study, it is found that $26 \mathrm{~mm}$ and $54 \mathrm{~mm}$ were the length of smallest and longest areca fiber respectively. Based on the fiber length, 10 groups were made in such a way that each successive group was greater than $3 \mathrm{~mm}$ length by the preceding group and the results are presented in Fig. 1. From Fig. 1 it is observed that the greatest number of areca fibers belongs to the group with an average fiber length of $39 \mathrm{~mm}$. Maximum numbers of areca fibers were found to be in the range of average length, 35-43 $\mathrm{mm}$ and it was about $71 \%{ }^{43-44}$.

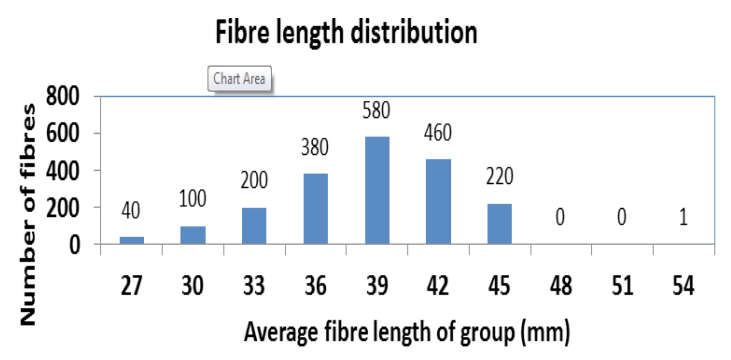

Fig.1. Fiber length distribution

\section{Fiber Diameter}

The diameter of areca fibers was measured at an interval of $5 \mathrm{~mm}$ along the length using Leica Stereo Microscopic Video Analyzer 2000 (Model 250D). The measurement was replicated three times and the mean diameter of fiber was calculated from the average of all the fibers in the group. The results are depicted in the Fig. 2. As the maximum number of areca fibers were found to be in the range of $35 \mathrm{~mm}$ to $43 \mathrm{~mm}$, the fibers of this group was considered in finding the average diameter. From Fig. 2, the diameter of the fiber groups with length $35-43 \mathrm{~mm}$ was found to be in the range of $0.347-0.37 \mathrm{~mm}$ and the average diameter of untreated areca fibers was found to be $0.362 \mathrm{~mm}$ and also it is observed that the short areca fibers have higher diameter. Further, assuming cylindrical shape for areca fibers, the aspect ratio was found to be 107.73 . 


\section{Fibre diameter distribution}

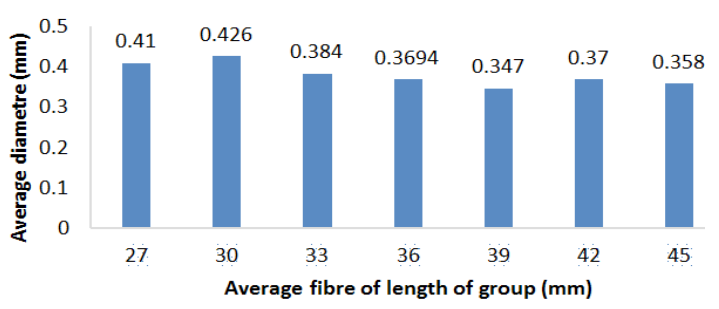

Fig. 2. Fiber diameter distribution

\section{Fibers Weight Distribution}

Weight of each fiber group was measured by using an electronic balance (Mettler Toledo; Model XS 64) with an accuracy of $0.1 \mathrm{mg}$ and the results are presented in Fig. 3. from Fig. 3, It was observed that the larger weight was distributed in fibers with length from $35 \mathrm{~mm}$ to $43 \mathrm{~mm}$ and it was about $55.2 \%$ of the total weight.

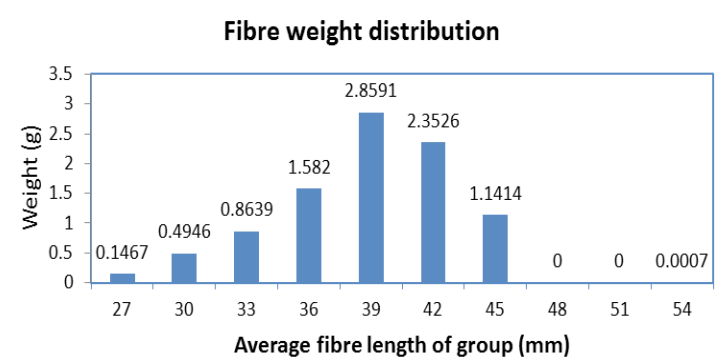

Fig. 3. Fibers weight distribution

\section{Fiber Density}

Areca catechu fiber density was determined using the principle of Archimedes according to ASTM D3800-99 (2010) and it was found to be $1.095 \mathrm{~g} / \mathrm{cm}^{3}$.

\section{Surface Modification}

The areca fiber used for the fabrication of polymer composite materials, face many problems because of the presence of hydrophilic groups on the fiber surface. Due to this hydrophilic nature of the fiber, the interfacial bonding between fiber and polymeric matrix is affected. Addition to this, lignin, pectin and some other waxy substances hinders the active functional groups of the fiber and behaves like a protector for reacting with the polymer materials. And also, bonding nature of natural fibers may vary from fiber to fiber as each fiber is different in their chemical composition. This type of problems can be overcome by modifying the surface of natural fibers through different chemical treatments.

\section{Tensile Strength}

Tensile tests were performed on single areca fiber to evaluate the tensile properties of areca fibers as showed in Table 2. In this test a comparison of the tensile properties of untreated areca fibers and alkali-treated areca fibers is performed. The data revealed that the untreated areca fibers exhibited higher tensile strength and Young's modulus values compared to the treate dareca fibers. This may be due to the changes in the crystallinity of cellulose upon alkali treatment ${ }^{45}$. The alkali treatment of fiber partially changes crystallinity of the cellulosic molecular structures by converting cellulose-I into more amorphous cellulose-II form, ruptures the ultimate cell wall partially, increase the deep pores and cause the thinning of fiber which results in poor tensile strength of treated fiber. Further, when the fibers are treated with alkali, it results in the partial removal of lignin as well as hemicellulose which acts as binding substance that holds the micro fibrils intact ${ }^{46}$. This results in reduced resistance of the areca fibers to withstand stretching causing the loose micro fibrils to rearrange along the tensile deformation direction, enhancing the elongation at break of natural fiber ${ }^{47-48}$.

Table 2: Mechanicalproperties of areca fiber

\begin{tabular}{|c|c|c|c|}
\hline \multirow[t]{2}{*}{ Fiber type } & \multicolumn{2}{|c|}{ Tensile strength Young's modulus } & \multirow{2}{*}{$\begin{array}{c}\text { Elongation at } \\
\text { break (\%) }\end{array}$} \\
\hline & (MPa) & (MPa) & \\
\hline Untreated & 97.69 & 598.46 & 16.3 \\
\hline Alkali treated & 70.13 & 355.52 & 19.59 \\
\hline
\end{tabular}

\section{Fiber Morphology}

Morphological studies were conducted by doing SEM measurements on the untreated fiber and the fiber surface resulting from tensile testing to provide an understanding on the effect of alkali treatment on areca fibers. Alkali treatment removes waxy epidermal tissue, adhesive nature of pectin, lignin and hemicelluloses that binds the fibers in bundles to each other ${ }^{49}$ and the results are presented in Fig. 4 and Fig. 5 for untreated and alkali treated areca fiber respectively. The SEM image of alkali treated fiber revealed the rough fiber surface, removal of hair like growths, trichomes ${ }^{50}$, which lead to the formation of pores on fiber surface due to elimination of waxy layer on the fiber surface upon alkali treatment. The presence of wax coating on the 
natural fiber surface prohibits effective interfacial bonding between natural fiber and polymer matrix ${ }^{31}$ and hence the elimination of this waxy layer, pectin, and low-molecular weight components from the surface of natural fiber may results in better contact between the fibers and the resin.

The Fig. 5 also revealed the thinning of fiber cell wall, formation of elongated structures and fibrillated microfibrils upon alkali treatment of fiber ${ }^{51}$. Hence, untreated natural fiber with thicker secondary cell wall and smaller lumen size area resulted in high tensile strength and Young's modulus. The decrease in fiber wall thickness due to alkali treatment also contributes to the reduction in fiber density, improvement in thermal conductivity and fiber specific properties of treated fiber. Thus, alkali treatment is a good option for enhancing the mechanical and thermal properties of areca fibers as reinforcement in polymer matrix composites.

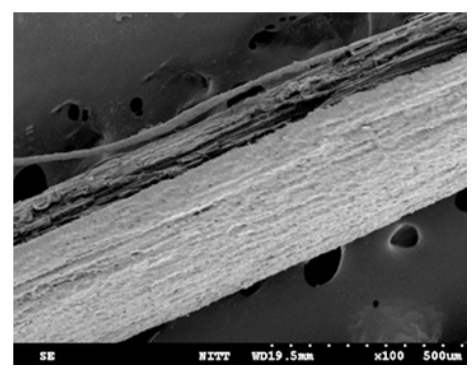

Fig. 4. SEM image of untreated fiber

\section{CONCLUSION}

Better compatibility between the hydrophilic

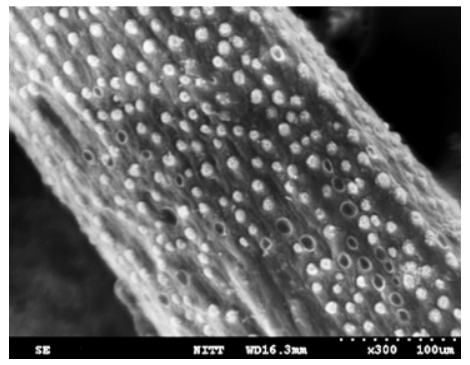

Fig. 5. SEM image of alkali treated fiber

natural fibers and the hydrophobic polymer matrix happens due to the surface modification by chemical treatments and as a result of it, strong binding between the modified fibers and a polymeric matrix will occurs which in turn improves the properties of natural fiber reinforced polymer composites. Morphological studies revealed the changes in surface topography for surface modified areca fiber when compared with that of unmodified areca fiber. Hence, surface modification of natural areca fiber by alkali treatment for reinforcement in polymer composites will definitely enhance the adhesion between the areca fibers and the polymeric resin forming better natural fiber polymer composites for a range of applications by replacing the synthetic origin.

\section{ACKNOWLEDGMENT}

This work was supported by Vision Group on Science and Technology (VGST), Department of IT, BT and S \& T, Government of Karnataka, India (grant number VGST/CISEE/2012-13/282 dated March 16, 2013.

\section{REFERENCE}

1. Jawaid, M., and Abdul Khalil, H. P. S. 7. Mohanty A. K.; Misra M.; and Hinrichsen G.; BioResources., 2011, 6, 2309-2322.

2. Panthapulakkal, S., and Sain, M. Compos., 2007, 38, 1445-1454.

3. Reddy, N., and Yang, Y. Polym. Eng. Sci., 2009, 49(11), 2212-2217.

4. SatyanarayanaK.G..; RavikumarK.K.;Sukumaran K..; Mukherjee P.S.; Pillai S. G. K.; and Kulkarni A. K., J. Mater. Sci.,1986, 21(1), 57-63.

5. Toriz G.; Arvidsson R.; Westin M. and Gatenholm P. J. Appl. Polym. Sci., 2003, 88(2), 337-345.

6. Wong S.; Shanks R.A.; and Hodzic A.; Macromol. Mater. Engg., 2002, 287, 647-655.

Macromol. Mater. Eng., 2000, 266-277(1), 1-24.

8. Afaghi-Khatibi A.; and Mai Y.W.; Composites., 33, 2002, 1585-1592.

9. Pothana L. A.; Oommenb Z.; and Thomas S.; Compos. Sci. Technol., 2003, 63(2), 283-293.

10. Luo S.; and Netravali A. N.; Polym.Composites., 1999, 20(3), 367-378.

11. Pavithran C.; Mukherjee P.S.; Brahmakumar M.; and Damodaran A. D., J. Mater. Sci. Lett., 1987, 6(8), 882-884.

12. Karmaker A.C.; and Schneider J. P., J. Mater. Sci. Lett., 1996, 15(3), 201-202. 
13. Gowda T.M.; Naidu A. C.B.; and Chhaya R.; Compos., 1999, 30(3), 277-284.

14. Okubo K.; Fujii T.; and Yamamoto Y., Compos. Part A-Appl. S., 2004, 35(3), 377-383.

15. Martins A.F.; Suarez J.C.M.; Visconte L.L.Y; and Nunes R.C.R., J. Mater. Sci., 2003, 38(11), 2415-2422.

16. Job A.B.; Oliveira F.A.; Alves N.N.; Giacometti J.A.; and Matosso L.A., Synth. Metals., 2003, 135-136, 831-837.

17. George J.; Bhagawan S.S.; and Thomas S., Compos. Interf., 1998, 5(3),201-223.

18. George J.; Bhagawan S.S.; Prabhakaran N.; and Thomas S., J. Appl. Polym. Sci.,1995, 57, 843-854.

19. Varghese S.; Kuriakose B.; and Thomas S., Stress relaxation in short sisal fibre-reinforced natural rubber composites, J. Appl. Polym. Sci.,1994, 53, 1051-60.

20. Varghese S.; Kuriakose B.; Thomas S.; and Koshy A. T., Ind. J. Nat. Rubb. Res., 1991, 4, 55.

21. Varghese S.; Kuriakose B.; Thomas S.; and Koshy A.T., J. Adhes. Sci. Technol., 1994, 8, 235-248.

22. Varghese S.; Kuriakose B.; and Thomas S., Rubb. Chem. Technol., 1995, 68(1), 37.

23. Joseph K.; Pavithran C.; and Thomas S., J. Appl. Polym. Sci., 1993, 47, 1731-1739.

24. Joseph K.; Pavithran C.; and Thomas S., Mater. Lett., 1992, 15, 224.

25. Joseph K.; Pavithran C.; and Thomas S., J. Reinf. Plast. Compos.,1993,12(2), 139-155.

26. Chakraborty S. K.; Setua D. K.; and De, S. K., Rubber Chem. Technol., 1982, 55, 1286-307.

27. Bledzki A.K.; and Gassan J., Prog. Polym. Sci.,1999, 24, 221-274.

28. Lai, C. Y.; Sapuan, S. M.; Yahya, M.; and Dahlan, K., Polym-Plast. Technol. Eng., 2005, 44(4), 619-632.

29. Jawaid.; M.; and Abdul Khalil, H. P. S., Compos., 2012, 43, 288-293.

30. Ramadevi, P.; Sampathkumar, D.; Srivinasa, C. V.; and Bennehalli, B., BioResources, 2012, 7(3), 3515-3524.

31. Mwaikambo, L. Y.; and Ansell, M., J. Appl. Polym. Sci., 2002, 84, 2222-2234.

32. Joseph K.; Pavithran C.; and Thomas S., J. Reinf. Plast. Compos.,1993,12(2), 139-155.

33. Mohanty A.K.; Khan M.A.; and Hinrichsen
G., Composites Part A: Applied Science and Manufacturing., 2000, 31(2), 143-150.

34. Bismarck A.; Mohanty A.K.; Aranberri Askargorta I.; Czapla S.; Misra M.; Hinrichsen G.; and Springer J., Green Chemistry., 2001, 3, 100-107.

35. Srinivasa, C. V.; and Bharath, K. N., J. Mater. Env. Sci., 2011, 2, 351-356.

36. Hassan, M.M.;Wagner, M.H.;Zaman, H.U.; and Khan, M. A. J. Nat. Fibers., 2010, 7, 165-177.

37. Yousif, B. F.; Nirmal, U.; and Wong, K. J. Mater. Des., 2010, 31, 4514-4521.

38. Nirmal, U.; Singh, N.; Hashim, J.; Lau, S.T.W.; and Jamil, N. Mater. Des., 2011, 32, 2717-2726.

39. L.Yusriah.; S.M. Sapuan.; Elsevier BV., 2018, 129-155.

40. Sampathkumar, D.; Punyamurthy, R.; Bennehalli, B.; and Venkateshappa, S. C., Int. J. Agric. Sci., 2012, 4(4), 227-229.

41. Chakrabarty J.; Hassan M. M.; and Khan M., J. Polym Environ., 2012, 20(2), 501-506.

42. Dhanalakshmi S.; Ramadevi P.; Srinivasa C.V. and Basavaraju B., Int. J. Agr. Sci., 2012, 4(4), 227-229.

43. Leonard Y. M.; and Ansell M. P., Die Angewandte Macromolecular Chemistry., 1999, 272(1), 109-110.

44. Huang G., Mater. Design., 2009, 30, 3931-3934.

45. Dhanalakshmi S.; Ramadevi P.; Raghu Patel G.R.; Manikanta M.; Kiran K.; Jayaraj A.; Jason M.; Chethan G.R.; and Basavaraju B., Cienciae-TecnicaVitivinicola., 2014, 29(8), 99-114.

46. Gomes, A.; Matsuo, T.; Goda, K.; and Ohgi, J., Compos., 2007, 38, 1811-1820.

47. Nitta, Y.; Goda, J.; and Lee, W-. II., Compos., 2013, 49, 132-138.

48. Rong, M. Z.; Zhang, M. Q., Liu, Y.; Yang, G. C.; and Zeng, H. M., Compos. Sci. Technol., 2001, 61, 1437-1447.

49. Punyamurthy Ramadevi.; Dhanalakshmi Sampathkumar.; Chikkol Venkteshappa Srinivasa.; and Basavaraju Bennehalli., BioResources., 2012, 7(3), 3515-3524.

50. Dhanalakshmi Sampathkumar.; Ramadevi Punyamurthy.; Basavaraju Bennehalli.; Srinivasa Chikkol Venkateshappa.; Ciência \& Tecnologia dos Materiais., 2015, 27, 121-135.

51. Sampath kumar, D.; Punya murthy, R.; Benne halli, B.; and Venkateshappa, S. C. Int. J. Agric. Sci., 2012, 4(4), 227-229. 